\title{
Amperometric Determination of Nicotine using a Composite of Palladium hexacyanoferrate incorporated Graphene oxide modified Electrode
}

\author{
Cheng Yu Yang, Min-Hui Chang, Shen-Ming Chen ${ }^{*}$, Balamurugan Devadas \\ Electroanalysis and Bio electrochemistry Laboratory, Department of Chemical Engineering and \\ Biotechnology, National Taipei University of Technology, No.1, Section 3, Chung-Hsiao East Road, \\ Taipei 106, Taiwan (ROC) \\ "E-mail: $\underline{\text { smchen78@ms15.hinet.net }}$
}

doi: $10.20964 / 110402650$

Received: 22 December 2015 / Accepted: 6 February 2016 / Published: 1 March 2016

\begin{abstract}
Herein, we report a highly sensitive amperometric nicotine (NIC) sensor using composite of palladium hexacyanoferrate (PdHCF) with graphene oxide (GO) modified glassy carbon electrode (GCE). The PdHCF particles were deposited on GO modified GCE using an electrochemical method. The electrocatalytic measurements and surface morphology of the as prepared composite modified electrode were studied using cyclic voltammetry, amperometry, electrochemical impedance spectroscopy and scanning electron microscopy. The PdHCF incorporated GO composite modified electrode exhibits a prominent electrocatalytic activity towards the NIC than that of other modified electrodes. Furthermore, the presence of GO with PdHCF has greatly enhanced the surface coverage concentration and electron transfer rate constant when compared to only PdHCF and GO. The composite modified electrode shows the linear range from 8 to $240 \mu \mathrm{M}$ for NIC with the analytical sensitivity of $1.208 \mu \mathrm{A} \mu \mathrm{M}^{-1} \mathrm{~cm}^{-2}$.
\end{abstract}

Keywords: Palladium hexacyanoferrate, graphene oxide, nicotine, amperometry, electrochemical method.

\section{$\underline{\text { FULL TEXT }}$}

(C) 2016 The Authors. Published by ESG (www.electrochemsci.org). This article is an open access article distributed under the terms and conditions of the Creative Commons Attribution license (http://creativecommons.org/licenses/by/4.0/). 